\title{
PENGEMBANGAN VIDEO PEMBELAJARAN PADA MATA PELAJARAN DASAR DESAIN GRAFIS KELAS X SMK NEGERI 40 JAKARTA
}

\author{
Ahmad Zainuri Fachri ${ }^{1}$, Hamidillah Ajie $^{2}$, Vina Oktaviani ${ }^{3}$ \\ ${ }^{1}$ Mahasiswa Prodi PendidikanTeknik Informatika dan Komputer, Teknik Elektro, FT - UNJ \\ ${ }^{2,3}$ Dosen Prodi Pendidikan Teknik Informatika dan Komputer, Teknik Elektro, FT - UNJ \\ ${ }^{1}$ ahmadzainurifachri@gmail.com, ${ }^{2}$ hamidillah@unj.ac.id, ${ }^{3}$ vinaoktaviani@unj.ac.id
}

\begin{abstract}
Abstrak
Penelitian ini bertujuan untuk mengembangkan video pembelajaran pada mata pelajaran Dasar Desain Grafis kelas X SMK Negeri 40 Jakarta. Dengan dibuatnya video pembelajaran ini diharapkan mampu membuat peserta didik dapat lebih mudah memahami fungsi-fungsi dasar tools pada toolbox Adobe Photoshop. Banyaknya tools pada Adobe Photoshop membuat proses pembelajaran yang membahas tentang Adobe Photoshop membutuhkan waktu lama. Oleh karna itu dikembangkanlah media pembelajaran berupa video pembelajaran yang dapat diakses dimanapun sehingga peserta didik dapat mempelajarinya diluar pembelajaran sekolah. Pengembangan video pembelajaran ini dilakukan melalui beberapa tahap yaitu: (1) perencanaan produk, (2) desain produk, (3) perencanaan konsep, (4) perancangan desain, (5) pengumpulan bahan, (6) pembuatan, (7) pengujian, dan (8) pendistribusian. Pada tahap pengujian oleh ahli materi hasil persentase nilai yang didapat yaitu $100 \%$ dan pada tahap pengujian oleh ahli media hasil persentase nilai yang didapat yaitu 89,3\%. Setelah dinyatakan layak oleh ahli materi dan ahli media, selanjutnya video pembelajaran diuji kepada responden yaitu peserta didik bidang keahlian Multimedia kelas X SMK Negeri 40 Jakarta dan mendapatkan hasil persentase nilai 91,85\%. Berdasarkan hasil pengujian tersebut, dapat disimpulkan bahwa video pembelajaran pengenalan dan pengguanaan dasar toolbox pada Adobe Photoshop layak digunakan dalam pembelajaran pada mata pelajaran Dasar Desain Grafis kelas X SMK Negeri 40 Jakarta.
\end{abstract}

Kata kunci : Video Pembelajaran, Adobe Photoshop, Dasar Desain Grafis

\section{Pendahuluan}

Sekolah Menengah Kejuruan (SMK) merupakan salah satu jenjang pendidikan menengah yang diharapkan menghasilkan lulusan yang siap bekerja. Oleh karena itu SMK memfokuskan peserta didik pada satu bidang keahlian agar peserta didik lebih memahami secara detail pelajaran dari bidang keahlian yang dipilih. Di SMK peserta didik lebih banyak menerima pembelajaran praktik dibanding teori. Pembelajaran ini bertujuan agar peserta didik terbiasa dan mampu dengan pekerjaan-pekerjaan yang akan diterima pada saat bekerja. Namun sebelum dilakukan praktik, guru tetap menerangkan terlebih dahulu tentang materi dasar yang akan dipraktikan.

SMK Negeri 40 Jakarta merupakan salah satu sekolah menengah kejuruan yang mempersiapkan peserta didik untuk memasuki dunia kerja. SMK Negeri 40 Jakarta memiliki berbagai macam bidang keahlian yaitu Administrasi Perkantoran, Akutansi, Pemasaran dan Multimedia. Pada bidang keahlian Multimedia terdapat mata pelajaran Dasar Desain Grafis. Mata pelajaran Dasar Desain Grafis mengenalkan peserta didik tentang ruang lingkup dasar dalam desain. Pada mata pelajaran ini peserta didik dituntut memiliki kemampuan dalam menggunakan perangkat lunak desain grafis, salah satu perangkat yang digunakan yaitu Adobe Photoshop.

Berdasarkan wawancara dan observasi awal kepada peserta didik kelas X di SMK Negeri 40 Jakarta pada bidang keahlian Multimedia mata pelajaran Dasar Desain Grafis, didapatkan hasil bahwa dari satu kelas yang berisi 35 peserta didik hanya 6 peserta yang sudah biasa menggunakan Adobe Photoshop, dan sisanya baru mengenal Adobe Photoshop. Sehingga masih banyak peserta didik yang belum memahami fungsi-fungsi toolbox pada Adobe Photoshop. Selain itu pada pelajaran Dasar Desain Grafis lebih banyak jumlah jam belajar praktik dibanding penyampaian materi saat pembelajaran Adobe Photoshop. Sementara pada penyampaian materi hanya membahas Adobe Photoshop secara umum saja.

Tool pada jendela Toolbox Adobe Photoshop CS6 berjumlah 52 dan setiap tool memiliki fungsi 
yang berbeda. Sedangkan untuk metode penyampaian materi yang digunakan pada penyampaian materi Adobe Photoshop adalah metode ceramah dan media yang digunakan hanya Power Point (PPT). Sehingga peserta didik sulit mengaplikasikan langsung materi yang disampaikan pada saat praktik berlangsung dan akhirnya memakan waktu lama pada saat proses pembelajaran.

Salah satu upaya yang dapat dilakukan adalah dengan menggunakan media pembelajaran berupa video pembelajaran. Video pembelajaran merupakan salah satu media pembelajaran berupa gambar bergerak (visual) yang disertai dengan suara (audio). Menurut Mayer dan Moreno (2003), diacu dalam Muhammad Rusli, dkk (2017: 89), sistem pemrosesan manusia terdiri dari dua saluran yaitu saluran audio/verbal dan visual/piktorial. Sehingga penggunaan video dalam penyampaian informasi saat pembelajaran dapat lebih mudah dicerna dan dipahami oleh peserta didik. Video pembelajaran dapat digunakan kapan, dan dimana saja serta dapat dilihat berulang-ulang untuk belajar, memudahkan peserta didik untuk mempelajari materi yang belum dipahami. Sehingga dengan adanya video ini maka peserta didik diharapkan dapat lebih memahami materi tentang Adobe Photoshop. Ketika praktik dilaksanakan peserta didik langsung dapat mengaplikasikannya.

Berdasarkan permasalahan yang ada, dibuatlah sebuah penelitian yang berjudul Pengembangan Video Pembelajaran Pada Mata Pelajaran Dasar Desain Grafis Kelas X SMK Negeri 40 Jakarta. materi yang dibahas dalam video adalah materi untuk mata pelajaran Dasar Desain Grafis tentang fungsi-fungsi toolbox pada Adobe Photoshop yang yang digunakan sebagai alat bantu dalam proses pembelajaran agar peserta didik dapat lebih mudah memahami fungsi-fungsi toolbox pada Adobe Photoshop.

\section{Dasar Teori}

\subsection{Adobe Photoshop}

Adobe Photoshop adalah perangkat lunak aplikasi untuk desain/perancangan foto/gambar, atau disebut photo design and production tools. Dengan Adobe Photoshop, beberapa macam manipulasi, diantaranya mengedit gambar, memperkecil, memperbesar, menggabungkan dan lain-lain dapat dilakukan dengan mudah. Adobe Photoshop diperlukan dalam pengolahan foto dan pembuatan gambar untuk background dari suatu tampilan. Gambar hasil dari Adobe Photoshop dapat diubah ke dalam format lain untuk digunakan pada pembuatan desain grafis, desain web dan lain-lain (Munir 2012: 17).

Dalam Adobe Photoshop terdapat Toolbox berisi tools yang digunakan sebagai alat dalam mendesain foto atau gambar. Toolbox merupakan palet yang berisi tombol-tombol perintah yang berguna untuk menggambar, memberi warna, menyunting, menyeleksi, memodifikasi gambar, menulis teks dan berbagai fungsi lainnya (Kok Yung, 2010: 2)

\subsection{Media}

Menurut Miarso (1989), diacu dalam Rudy Sumiharsono dan Hisbiyatul Hasana (2017: 3) media adalah segala sesuatu yang dapat digunakan untuk menyalurkan pesan yang dapat merangsang pikiran, perasaan, perhatian, dan kemauan siswa untuk belajar.

Sedangka Gerlach \& Ely, diacu dalam Cecep Kustandi dan Bambang Sutjipto (2011: 7) mengatakan bahwa media apabila dipahami secara garis besar adalah manusia, materi, atau kejadian yang mendukung kondisi.

\subsection{Pembelajaran}

Menurut Cecep Kustandi dan Bambang Sutjipto (2011: 8) mengatakan bahwa media pembelajaran adalah sarana untuk meningkatkan kegiatan proses belajar mengajar.

Menurut Saifuddin (2014: 142) media pembelajaran adalah media yang memungkinkan terjadinya interaksi antara produk pengembang media dan peserta didik/pengguna. Atau dengan kata lain peran pendidik sebagai penyampai materi pembelajaran digantikan oleh media.

\subsection{Media Pembelajaran}

Menurut Cecep Kustandi dan Bambang Sutjipto (2011: 8) mengatakan bahwa media pembelajaran adalah sarana untuk meningkatkan kegiatan proses belajar mengajar.

Menurut Saifuddin (2014: 142) media pembelajaran adalah media yang memungkinkan terjadinya interaksi antara produk pengembang media dan peserta didik/pengguna. Atau dengan kata lain peran pendidik sebagai penyampai materi pembelajaran digantikan oleh media.

Berdasarkan pendapat diatas dapat disimpulkan bahwa media pembelaran adalah suatu sarana yang digunakan dalam penyampaian pembelajaran.

\section{Metodologi}

\subsection{Tempat dan Waktu Penelitian}

Penelitian ini dilaksanakan di Perpustakaan Universitas Negeri Jakarta. Pengujian hasil penelitian dilakukan di SMK Negeri 40 Jakarta

\subsection{Metode Pengembangan Produk}

Pada penelitian ini digunakan metode $R \& D$ (Research and Development). Metode R\&D digunakan sebagai metode untuk menghasilkan 
suatu produk sesuai dengan tujuan penelitian yang dibuat yaitu video tutorial.

Adapun model pengembangan yang digunakan dalam penelitian ini adalah model pengembangan MDLC dari Luther (1994) yang dimodifikasi oleh sutopo (2003).

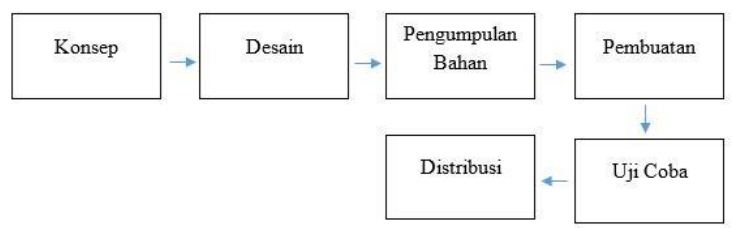

Gambar 3.1 Tahap Desain Produk

\subsection{Prosedur Pengembangan}

Dalam mengembangkan media pembelajaran berbasis video tutorial untuk menyampaikan materi tentang toolbox Adobe Photoshop diperlukan penelitian pendahuluan berupa analisis kinerja dan analisis kebutuhan untuk mengetahui apakah permasalahan yang terjadi membutuhkan solusi berupa pengembangan media pembelajaran serta apa saja yang dibutuhkan dalam mengembangkan media pembelajaran tersebut. Dalam menganalisis kinerja dan kebutuhan, pada tahapan penelitian ini menggunakan metode sebagai berikut:

1. Metode Observasi. Observasi yang dilakukan adalah pengamatan langsung untuk memperoleh data yang mendukung penelitian. Data ini digunakan untuk menggali informasi berkaitan dengan keadaan sekolah, permasalahan, kendala dalam proses pembelajaran di sekolah serta kondisi atau keadaan pada waktu pembelajaran.

2. Metode Wawancara. Metode ini wawancara digunakan untuk memperoleh informasi melalui guru mengenai metode yang dipakai dalam menyampaikan materi Adobe Photoshop khususnya pengenalan toolbox serta cara penggunaannya dalam belajar dan media pembelajaran apa yang digunakan sebelumnya sehingga peserta didik masih sulit memahami materi yang dijelaskan.

\subsection{Teknik Pengumpulan Data}

Teknik pengumpulan data yang digunakan pada penelitian pengembangan video pembelajaran pada mata pelajaran Dasar Desain Grafis kelas X SMK Negeri 40 Jakarta yaitu dengan melakukan wawancara terhadap guru serta dan peserta didik. Teknik wawancara yang digunakan adalah wawancara tidak terstruktur. Menurut Susilo Rahardjo dan Gudnanto (2013: 133) wawancara tidak terstruktur merupakan kegiatan wawancara yang belum menentukan hal-hal (materi) yang akan ditanyakan oleh interviewer. Wawancara tidak terstruktur memberikan kebebasan lebih luas kepada pihak pewawancara untuk berimprovisasi dan menanyakan hal-hal tertentu yang dianggapnya relevan dengan permasalahan yang hendak diketahui atau topik tertentu yang sedang diteliti (Purbayu Budi Santosa \& Mulyawan Hamdani, 2007: 16).

\subsection{Teknik Analisis Data}

Penelitian ini menggunakan dua ahli, yaitu ahli materi dan ahli media serta responden. Pada kisi-kisi instrumen ahli materi dan responden menggunakan skala Guttman. Menurut Sopingi (2015: 46) skala Guttman adalah skala yang menginginkan tipe jawaban tegas, seperti jawaban benar-salah, yatidak, pernah-tidak pernah, positif-negatif, tinggirendah, baik-buruk, dan seterusnya. Skala Guttman dapat dibuat dalam bentuk pilihan ganda maupun daftar checklist. Pada penelitian ini menggunakan bentuk checklist.

Sedangkan kisi-kisi instrumen ahli media menggunakan skala Likert. Skala Likert ialah skala yang dapat dipergunakan utuk mengukur sikap, pendapat, dan presepsi seseorang atau sekelompok orang tentang suatu gejala atau fenomena pendidikan. Ada dua bentuk pertanyaan yang menggunakan skala Likert yaitu bentuk pertanyaan positif untuk mengukur sikap positif, dan bentuk pertanyaan negatif untuk mengukur sikap nrgatif. Pertanyaan positif diberi skor 5, 4, 3, 2, dan 1, sedangkan bentuk pertanyaan negatif diberi skor 1,2,3,4 dan 5 atau $-2,-1,0,1,2$. Bentuk jawaban skala Likert ialah sangat setuju, setuju, ragu-ragu, tidak setuju, dan sangat tidak setuju (Djaali dan Pudji Mulyono, 2007: 28).

Tabel 3.1 Aspek, Komponen Dan Butir Uji Ahli Materi

\begin{tabular}{|c|c|}
\hline Aspek & Komponen \\
\hline $\begin{array}{l}\text { I. Kelayakan } \\
\text { Isi }\end{array}$ & $\begin{array}{ll}\text { a. Kesesuaian materi dengan } \\
\text { tujuan pembelajaran } \\
\text { b. Keakuratan isi } \\
\text { c. Kemutakhiran isi } \\
\text { d. Mendorong keingin tahuan }\end{array}$ \\
\hline $\begin{array}{l}\text { II. Kelayakan } \\
\text { Penyajian }\end{array}$ & $\begin{array}{ll}\text { a. } & \text { teknik penyajian } \\
\text { b. pendukung penyajian } \\
\text { c. penyajian pembelajaran } \\
\text { d. koherensi dan keruntutan } \\
\text { alur pikir }\end{array}$ \\
\hline $\begin{array}{c}\text { III. Kelayaka } \\
\text { Bahasa }\end{array}$ & $\begin{array}{ll}\text { a. } & \text { Kelugasan } \\
\text { b. Komunikatif } \\
\text { c. Diagnosis \& interaktif } \\
\text { d. Sesuai perkembangan } \\
\text { peserta didik } \\
\text { e. Kesesuaian dengan kaidah } \\
\text { bahasa Indonesia } \\
\text { f. Penggunaan istilah, simbol, } \\
\\
\text { ikon }\end{array}$ \\
\hline
\end{tabular}


Tabel 3.2 Aspek, Komponen Dan Butir Uji Ahli Media

\begin{tabular}{|l|l|}
\hline \multicolumn{1}{|c|}{ Aspek } & \multicolumn{1}{|c|}{ Komponen } \\
\hline I. Elemen Teks & Typeface, warna \\
\hline $\begin{array}{l}\text { II. Elemen } \\
\text { Grafis/Visual }\end{array}$ & $\begin{array}{l}\text { Gambar, foto, bagan, } \\
\text { grafik, ilustrasi, simbol, dan } \\
\text { ikon serta warna. }\end{array}$ \\
\hline $\begin{array}{l}\text { III. Elemen Audio } \\
\text { IV. Elemen Audio } \\
\text { Visual }\end{array}$ & $\begin{array}{l}\text { Suara narasi (dubber), } \\
\text { suara efek, musik latar. }\end{array}$ \\
\hline $\begin{array}{l}\text { V. Kemasan } \\
\text { Video, clip dan narasi. }\end{array}$ \\
\hline $\begin{array}{l}\text { VI. Kelengkapan } \\
\text { Bahan Ajar }\end{array}$ & $\begin{array}{l}\text { Pisual grafik, spesifikasi } \\
\text { produk, format media dan } \\
\text { identitas pengembang. dosen, petunjuk } \\
\text { Mahasiswa. }\end{array}$ \\
\hline
\end{tabular}

Tabel 3.3 Aspek, Komponen Dan Butir Uji Responden

\begin{tabular}{|l|l|}
\hline \multicolumn{1}{|c|}{ Aspek } & \multicolumn{2}{|c|}{ Komponen } \\
\hline Tampilan Video & Tampilan video \\
& menarik perhatian. \\
\hline Isi Materi & Sesuai dengan \\
& kebutuhan, Mudah \\
& dipahami, mendapatkan \\
& pemahaman tentang \\
& masing-masing toolbox \\
& pada Adobe Photoshop. \\
\hline Ketertarikan & $\begin{array}{l}\text { Meningkatkan minat } \\
\text { untuk mengikuti } \\
\end{array}$ \\
& pelajaran. \\
\hline
\end{tabular}

Setelah memperoleh data hasil evalusi produk oleh ahli materi, ahli media, dan responden dilakukan analisis data. Pada hasil evaluasi ahli materi dan ahli media anlisis data dilakukan dengan teknik analisis deskriptif. Analisis deskriptif merupakan metode analisis yang bertujuan mendeskripsikan atau menjelaskan sesuatu hal apa adanya (Irawan, 2004, diacu dalam Ali Baroroh,2008: 1).

Data berdasarkan angket akan dilihat hasil persentase untuk setiap pertanyaan yang kemudian akan dideskripsikan. Persentase tersebut menggunakan rumus sebagai berikut:

$$
\begin{aligned}
& \text { keterangan } \\
& \boldsymbol{P}=\text { Persentase } \\
& \boldsymbol{f}=\text { Frekuensi dari setiap } \\
& P=\frac{f}{n} x \mathbf{1 0 0} \% \quad \begin{array}{l}
f=\text { Fre } \\
\text { angket }
\end{array} \\
& \boldsymbol{n}=\text { jumlah skor ideal }
\end{aligned}
$$

Hasil persentase digunakan untuk memberikan jawaban atas kelayakan dari aspekaspek yang diteliti. Pembagian kategori kelayakan menurut Arikunto ada lima. Skala ini memperhatikan rentang dari bilangan presentase. Nilai maksimal yang diharapkan adalah $100 \%$ dan minimum $0 \%$. Pembagian retang kategori kelayakan dapat dilihat pada Tabel 3.4.

Tabel 3.4 Kategori Kelayakan

\begin{tabular}{|c|l|c|}
\hline No & \multicolumn{1}{|c|}{ Kategori } & Presentasi \\
\hline 1 & Sangat baik & $81 \%-100 \%$ \\
\hline 2 & Baik & $61 \%-80 \%$ \\
\hline 3 & Cukup baik & $41 \%-60 \%$ \\
\hline 4 & Kurang baik & $21 \%-40 \%$ \\
\hline 5 & Tidak baik & $<21 \%$ \\
\hline
\end{tabular}

\section{Hasil Penelitian Dan Pembahasan}

\subsection{Hasil Pengembangan Produk}

Hasil dari pengembangan produk berupa video pembelajaran toolbox Adobe Photoshop untuk mata pelajaran Dasar Desain Grafis kelas X bidang keahlian Multimedia di SMK Negeri 40 Jakarta. Pengembangan video pembelajaran bertujuan untuk membantu peserta didik dalam proses pembelajaran di dalam kelas maupun di luar kelas dan juga dapat menambah referensi peserta didik dalam mempelajari materi fungsi-fungsi toolbox pada Adobe Photoshop.

Toolbox pada Adobe Photoshop memiliki 52 tools sehingga durasi dalam video akan panjang, oleh sebab itu video akan dibuat menjadi enam bagian dimana setiap bagian memiliki durasi kurang lebih 10 menit sehingga total keseluruhan sekitar 1 jam.

Masing-masing video memiliki pembukaan, isi, dan penutup. Pembukaan meliputi bumper (logo UNJ dan SMK Negeri 40), judul video pembelajaran, pembukaan dari host, dan menampilkan nama tools yang akan dibahas.

Isi berupa deskripsi singkat dari masingmasing tool yang dibahas serta cara penggunaan dasarnya. Tampilan antarmuka pada isi berupa nama tools, deskripsi, dan logonya serta tampilan jendela kerja Adobe Photoshop saat menjelaskan cara penggunaan tools.

\subsection{Kelayakan Produk}

Setelah produk video pembelajaran selesai dibuat maka dilakukan validasi dan di uji oleh ahli materi dan ahli media. Pengujian ini bertujuan untuk mengetahui apakah video pembelajaran sudah layak atau masih perlu dilakukan perbaikan. Ahli materi akan menguji kelayakan produk dari segi materi yang disampaikan, sedangkan ahli media akan menguji kelayakan produk dari segi media yang ditampilkan.

Pengujian produk oleh ahli materi menggunakan sekala Gutman dengan dua pilihan jawaban, yaitu YA dengan skor 1 atau TIDAK dengan skor 0 , sedangkan pengujian produk oleh 
ahli media menggunakan skala likert dengan rentan nilai 1 sampai 5 dimana $1=$ sangat tidak setuju, $2=$ tidak setuju, $3=$ cukup setuju, $4=$ setuju, dan $5=$ sangat setuju.

Nilai presentasi produk dari uji ahli materi adalah $100 \%$ dan pada tahap pengujian oleh ahli media adalah $89,3 \%$. Dari hasil penilaiyan tersebut maka produk dinyatakan layak dan lanjut ke tahap pengujian oleh responden yaitu peserta didik kelas X Multimedia SMK Negeri 40 Jakarta.

Pengujian produk kepada responden menggunakan skala likert dengan rentan nilai 1 sampai 5 dimana 1 = sangat tidak setuju, $2=$ tidak setuju, $3=$ cukup setuju, $4=$ setuju, dan $5=$ sangat setuju. Setelah diuji oleh responden hasil nilai presentase yang didapat yaitu $91,85 \%$. Berdasarkan hasil pengujian tersebut, dapat disimpulkan bahwa video pembelajaran pengenalan dan pengguanaan dasar toolbox pada Adobe Photoshop layak digunakan dalam pembelajaran pada mata pelajaran Dasar Desain Grafis kelas X SMK Negeri 40 Jakarta.

\subsection{Pembahasan}

Video pembelajaran tentang fungsi dasar toolbox Adobe Photoshop dibuat untuk membantu proses pembelajaran Dasar Desain Grafis kelas X pada bidang keahlian Multimedia di SMK Negeri 40 Jakarta. Dalam video pembelajaran terdapat tampilan teks, ikon, dan juga tampilan layar kerja Adobe Photoshop. Tampilan teks berisi kalimat penjelasan fungsi dasar toolbox Adobe Photoshop, ikon yang ditampilkan adalah ikon dari masingmasing toolbox, dan layar kerja Adobe Photoshop menampilkan rekaman cara menggunakan masingmasing tools sesuai dengan fungsi yang sudah dijelaskan.

Dalam proses pengembangan video pembelajaran ini terdapat faktor pendukung dan faktor penghambat, diantaranya:

1. Faktor Pendukung

a. SMK Negeri 40 Jakarta memiliki laboratorium Multimedia dan komputer yang digunakan terdapat software Adobe Photoshop, sehingga peserta didik dapat mempraktikan langsung hasil dari materi yang disampaikan pada video pembelajaran.

b. Peneliti menguasai dasar editing video dengan menggunakan adobe premiere.

2. Faktor Penghambat

a. Terbatasnya waktu dalam pengembangan produk sehingga masih banyak kekurangan.

b. Kurangnya alat kerja untuk pengumpulan bahan yang akan di masukan kedalam video. Sehingga tampilan video yang dihasilkan kurang baik.

\section{Kesimpulan, Implikasi, dan Saran}

\subsection{Kesimpulan}

Berdasarkan hasil penelitian dan pengembangan media pembelajaran berupa video pada mata pelajaran Dasar Desain Grafi Kelas X SMK Negeri 40 Jakarta yang bertujuan agar peserta didik dapat lebih mudah memahami fungsi-fungsi toolbox pada Adobe Photoshop, maka dapat ditarik kesimpulan yaitu:

1. Setelah video pembelajaran tentang fungsi dasar tools dan cara kegunaannya diuji oleh ahli materi dan ahli media didapati hasil nilai persentase $100 \%$ untuk isi materi dan $89,3 \%$ untuk tampilan media dan masuk kategori "Sangat Baik", sehingga dinyatakan layak untuk diimplementasikan.

2. Tahap implementasi dilakukan pada peserta didik kelas X Multimedia SMK Negeri 40 Jakarta. Setelah produk diuji oleh 21 peserta didik diperoleh hasil nilai persentase $91,85 \%$ dan masuk kategori nilai "Sangat Baik".

\subsection{Implikasi}

Dengan adanya video pembelajaran tentang fungsi dasar tools pada Adobe Photoshop membantu proses belajar pada mata pelajaran Dasar Desain Grafis kelas X dan memudahkan peserta didik dalam memahami fungsi dan cara penggunaan masingmasing tool pada Adobe Photoshop serta menarik peseta didik untuk mempelajarinya.

\subsection{Saran}

Selama proses penelitian dan pengembangan, ada beberapa hal yang dipertimbangakan untuk penelitian selanjutnya, antara lain:

1. Media video pembelajaran fungsi dan cara penggunaan tools Adobe Photoshop digunakan hanya sebagai pendukung dalam proses belajar peserta didik baik disekolah maupun dirumah.

2. Perlu penggunaan alat perekam suara yang baik agar suara yang dihasilkan lebih terdengar jelas dan jernih.

\section{Daftar Pustaka:}

Alfianika, Ninit. (2016). Metode Penelitian Pengajaran Bahasa Indonesia. Yogyakarta: DEEPUBLISH.

Baroro, Ali. (2008). Trik-trik Analisis Statistik Dengan SPSS15. Jakarta: PT Elex Media Komputindo.

Binanto, Iwan. (2010). Multimedia Digital Dasar Teori + Pengembangannya. Yogyakarta: C.V ANDI OFFSET.

Djaali \& Muljono, Pudji. (2006). Pengukuran Dalam Bidang Pendidikan. Jakarta: PT Grasindo. 
Hakim, Lukmanul \& Mutmainah, Siti. (2003). Membuat Grafik Web Yang Menarik Dengan Photoshop. Jakarta: PT Elex Media Komputindo.

Jalinus, Nizwardi \& Ambiyar. (2016). Media \& Sumber Pembelajaran. Jakarta: Kencana.

Kustandi, Cecep \& Sutjipto, Bambang. (2011). Media Pembelajaran Manual Dan Digital. Bogor: Ghalia Indonesia.

Munir. (2012). Multimedia Konsep \& Aplikasi Dalam Pendidikan. Bandung: Alfabeta.

Rahardjo, Susilo \& Gudnanto. (2013) Pemahaman Individu Teknik Nontes. Ed rev. Jakarta: Kencana.

Riyanto, Slamet. (2006). Praktikum Adobe Photoshop CS. Bogor: Slamet Riyanto.

Riyana, Cepy. (2009). Media Pembelajaran. Ed ke1. [penerbit tidak diketahui].

Rusli, Muhammd., Hermawan, Dadang., \& Supuwiningsih, Ni Nyoman. (2017). Multimedia Pembelajaran Yang Inovatif Prinsip \& Model Pengembangan. Yogyakarta: Andi.

Sagala, Syaiful. (2003). Konsep Dan Makna Pembelajaran. Bandung: Alfabeta.

Saifuddin. (2014). Pengelolaan Pembelajaran Teoretis Dan Praktis. Yogyakarta: DEEPUBLISH.

Sanjaya, Wina. (2006). Strategi Pembelajaran Berorientasi Standar Proses Pendidikan. Jakarta: Kencana.

Santosa, Purbayu Budi \& Hamdani, Muliawan. (2007). Statistika Deskriptif Dalam Bidang Ekonomi Dan Niaga. Jakarta: Erlangga.

Sopingi. (2015). Pengantar Statistik Pendidikan Jilid 1. Malang: GUNUNG SAMUDERA.

Sutarti, Tatik \& Irawan, Edi. (2017). Kiat Sukses Meraih Hibah Penelitian Pengembangan. Yogyakarta: DEEPUBLISH.

Sumiharsono, Rudy \& Hasanah, Hisbiyatul. (2017). Media Pembelajaran. Ed ke-1. Jember: CV PUSTAKA ABADI.

Yung, Kok. (2010). 159 Teknik Profesional Photoshop CS5. Jakarta: PT Elex Media Komputindo. 